\title{
Assessing right ventricular function in pulmonary hypertension patients and the correlation with the New York Heart Association (NYHA) classification
}

\author{
Xiaoke Shang ${ }^{1, *}$, Shuna Xiao ${ }^{2, *}$, Nianguo Dong ${ }^{1}$, Rong Lu ${ }^{3}$, Lijun Wang ${ }^{4}$, Bin Wang ${ }^{1}$, \\ Yousan Chen ${ }^{5}$, Liang Zhong ${ }^{6,7}$ and Mei Liu ${ }^{3}$ \\ ${ }^{1}$ Department of Cardiovascular Surgery, Union Hospital, Tongji Medical College, Huazhong University of Science and \\ Technology, Hubei Province 430222, China \\ ${ }^{2}$ Department of Pediatric Intensive Care Unit, Hubei Maternal and Child Health Hospital, Hubei Province 430070, China \\ ${ }^{3}$ Department of Intensive Care Unit, Wuhan No.1 Hospital, Tongji Medical College, Huazhong University of Science and \\ Technology, Hubei Province 430222, China \\ ${ }^{4}$ Department of Intervention, Wuhan Asia Heart Hospital, Hubei Province 430022, China \\ ${ }^{5}$ Department of Radiology, Wuhan General Hospital of CPLA, Guangzhou Military Command, Hubei Province 430070, China \\ ${ }^{6}$ National Heart Centre Singapore, 169609, Singapore \\ ${ }^{7}$ Duke NUS Medical School, 169857, Singapore \\ *These authors contributed equally to this work
}

Correspondence to: Rong Lu, email: sxs_Ir@163.com

Keywords: right ventricular, pulmonary hypertension (PH), New York Heart Association (NYHA), PV Loop

Received: February 23, $2017 \quad$ Accepted: June 17, $2017 \quad$ Published: July 05, 2017

Copyright: Shang et al. This is an open-access article distributed under the terms of the Creative Commons Attribution License 3.0 (CC BY 3.0 ), which permits unrestricted use, distribution, and reproduction in any medium, provided the original author and source are credited.

\section{ABSTRACT}

This investigation aimed to compare the pressure-volume loop (PV loop) measurements in three less symptomatic categories (New York Heart Association classes, NYHA I, II, and III) of pulmonary hypertension (PH) patients since NYHA classification system performance is limited by the shortcomings discussed above.

Thirty-six patients were enrolled in this study with PV loop measurement acquisition via micro-conductance catheters. Functional classification according to NYHA was determined with comprehensive assessing function and activity. Catheterization and MRI was applied to obtain variables on right ventricle (RV) functions. Correlation test was applied to test the relationship between measured PV loop measurements and NYHA classification.

A group of PV loop measurements, including end-systolic pressure (RVESP) RV end-diastolic pressure (RVEDP), and RV arterial elastance (RVEa), are well correlated with three NYHA classes (I, II, and III). Moreover, RVESP and RVEa significantly correlated with two groups of NYHA classes (I and II/III) while RVEDP, RV end-diastolic volume (RVEDV), and RV end-systolic volume (RVESV) significantly moderately correlated with two groups of NYHA classes (I/II and III). This study suggests the promising role of PV loop analysis in assessing functional capacity in progressive but less symptomatic $\mathrm{PH}$ patients.

\section{INTRODUCTION}

Pulmonary Hypertension (PH), defined by a mean pulmonary artery pressure $\geq 25 \mathrm{~mm} \mathrm{Hg}$, is a progressive disorder and a fatal disease with only a $58 \%$ survival rate at 3 years [1]. It is a type of high blood pressure that affects the pulmonary vascular system, primarily the small pulmonary arterioles. Though the initial syndrome of $\mathrm{PH}$ involves the pulmonary vasculature, this disease normally leads to hypertrophy of the right ventricle and reduced cardiac output, eventually causing right heart failure or death $[2,3]$. Chronic heart failure remains a serious and 
burdensome healthcare issue, and carries a poor prognosis. The New York Heart Association (NYHA) classification system was first developed in 1928 and most recently revised in 1994 [4]. Despite this powerful prognostic ability, NYHA classification remains an approximate and subjective system by definition; it seems to perform well in more symptomatic patients in classes III and IV, but becomes more subjective when there are fewer symptoms and can make it challenging to consistently classify patients between classes II and III, or between classes I and II $[5,6]$. However, this classification should not be abandoned as it provides a rapid assessment of patients' functional status in everyday clinical practice and is a well established means of predicting prognosis when applied to dichotomously divided patients [5-8]. It is therefore suggested that functional capacity assessment is, fundamentally, an overwhelmingly important prognostic element [5] that could overcome NYHA's limitations in less symptomatic $\mathrm{PH}$ patients.

The gold standard for detailed ventricular functional capacity is the pressure-volume (PV) relationship that measures the total mechanical energy of the ventricle and its efficiency as a heat engine and pump, which allows myocardial contractile efficiency to be determined [9]. First proposed by Frank [10] and later thoroughly studied by Suga et al in the 1970s $[9,11,12]$, this pressure-volume relationship is capable of determining a considerable amount of information regarding cardiac performance [13]. Conceptually, the pivotal studies using end-systolic and end-diastolic pressure-volume relationships show the ventricular contractility through end-systolic elastance (Ees), the ventricular afterload through arterial elastance (Ea), and the flow output at minimal energy cost (Ees/Ea) $[13,14]$. This PV loop analysis is accomplished through non-invasive magnetic resonance imaging (MRI) and invasive catheterization combined in a single heartbeat $[13,15-18]$. Since it was first conducted decades ago, this analysis has been widely applied in left ventricular (LV) analysis [19, 20]. However, because right heart failure was thought to be less important and the right ventricle (RV) operates at lower pressures than the left ventricle and the systemic arteries [14], the quantitative analysis and functional prognosis of the right ventricle in $\mathrm{PH}$ patients have been less intensively studied than the widely studied left ventricle. The lack of adequate PV loop analysis on $\mathrm{RV}$ function in $\mathrm{PH}$ patients is at odds with the increasing demands on both clinical management of $\mathrm{PH}$ patients and clinical research [21] and hinders the establishment of a combined prognosis based on $\mathrm{PH}$ patients' functional assessment and the popular but subjective NYHA system.

Therefore, this investigation aimed to compare the PV loop measurements in three less symptomatic categories of PH patients (NYHA classes I, II, and III) categories for which the NYHA classification system performance is limited by the shortcomings discussed above. We also evaluated the prognostic ability of the PV loop measurements in assessing the cardiac functional capacity of $\mathrm{PH}$ patients.

\section{MATERIALS AND METHODS}

\section{Ethics statement and informed consent}

With regards to the retrospective nature of this research, the protocol was approved by the review board at Wuhan Asia Heart Hospital. And the authors pledge to abide by the declaration of Helsinki (1996 EDITION). Informed consent was obtained from the parent or legal guardian (age $<18$ years) or from the patient (age $\geq 18$ ). Additionally, no intervention was given in participations and the patients' personal information is being kept confidential.

\section{Patients and functional classification}

Thirty-six patients (with a mean age of $32.81 \pm 12.20$ years) were enrolled in this study with PV loop measurement acquisition via micro-conductance catheters. The inclusion criteria are based on the RV micro-conductance and Cardiac Magnetic Resonance (CMR) imaging results. The exclusion criteria are: 1) Prothrombin Time International Normalized Ratio (PTINR test) $>1.6$; 2) platelet count $<50,000 ; 3$ ) patients who are incapable of being performed a surgery with supine position; 4) patients who are allegic to intravenous contrast medium; 5) creatinine $(\mathrm{Cr})$ value greater than $2.0 ; 6)$ patients who have atherosclerosis and coronary artery diseases, cancers, diabetes, high cholesterol symptoms, elevated homocysteine levels, metabolic syndrome, and/or blood diseases. The PH diagnosis was established according to the practice guidelines of the American College of Cardiology [22], with the medical history inspection. Functional classification according to NYHA was determined with comprehensive assessing function and activity [4]. It was tried to ensure that the classification would give a comprehensive summary of the patient's clinical condition. The PV loop parameters were not the determinants or the criteria on this classification.

\section{Right heart catheterization}

Catheterization was done in the catheterization laboratory with the patients under conscious sedation and local anesthesia. The following invasive hemodynamic variables were recorded: mean right atrial pressure (mRAP), RV pressure, mean pulmonary arterial pressure (mPAP), and total peripheral resistance (TPR). Enddiastolic pressure (EDP) was recorded at the maximal diastolic filling pressure point before the onset of isovolumetric contraction. Diastolic filling pressures were acquired at the minimum pressure point after tricuspid valve opening. End-systolic pressure (ESP) was obtained at the end of the systolic process. 


\section{Cardiac MRI}

MRI observation time was approximately $20-30 \mathrm{~min}$, and it took another $20 \mathrm{~min}$ for the image processing and recording. RV volumes were calculated with Mass software (MEDIS; Medical Imaging Systems, Leiden, Netherlands) from multiple short axial slice MRI analysis [23]. End-systolic volume (ESV) was referred to as begin-diastolic volume (BDV). End-systolic volume was considered to correspond to BDP and is further referred to as begin-diastolic volume, and end-diastolic volume (EDV) corresponded to EDP. Stroke volume (SV) was calculated from MRI-derived pulmonary artery flow and used to accurately determine RV BDV. RV volumetric filling curves were obtained from the stack of short axis cine images [24, 25].

\section{Pressure-volume analysis}

The single beat method [26] was employed to calculate elastance-related measurements, i.e., end-systolic elastance (Ees), arterial elastance (Ea), and their ratio (Ees/Ea), as described in [27]; ESP was approximated by mPAP. Ees was then calculated as the slope of endsystolic PV relationship (the difference between maximum pressure (Pmax) and mPAP, all divided by SV), and Ea was estimated by the ratio of mPAP to SV. The single beat method allows for the definition of ESP that is a line drawn from Pmax tangent to the RV pressure-volume loop with relative variation in volume calculated from the integration of pulmonary flow (Figure 1).

\section{Statistical analysis}

Data are expressed as mean \pm standard deviation (SD). Statistical significance was defined as two-sided $p$ value $<0.05$. All statistical analysis was performed with commercially available software (SPSS for Windows, version 19.0; SPSS Inc., Chicago, IL). The Spearman correlation test was applied to test the relationship between measured PV loop measurements and NYHA classification. The NYHA class was predicted by Receiver Operating Characteristic (ROC) analysis. A two-tailed $P$ value smaller than 0.05 was considered and applied to all statistical testing as statistically significant.

\section{RESULTS}

\section{Basic characteristics of the subjects}

A total of $36 \mathrm{PH}$ patients (10 male) were enrolled, with a mean age of $32.81 \pm 12.20$ years and a 6 -minute walk distance of $446.42 \pm 11.29$ meters. Five of the patients were in NYHA class I, 23 were in class II, and 8 were in class III. No severe symptomatic patients (class IV) were included in this study. The patients' mean pulmonary arterial pressure (mPAP) was $55.19 \pm 20.41$ $\mathrm{mm} \mathrm{Hg}$ (range: 10.00 to 92.00 ). $16.7 \%$ of the patients had chest pain, $47.2 \%$ had chest distress, $16.7 \%$ had hemoptysis, $44.4 \%$ had cyanosis, $41.7 \%$ had dyspnea, and $33.3 \%$ had peripheral edema on their medical history. Overall patient characteristics are summarized in Table 1.

Detailed patient characteristics in different NYHA classes were analyzed and are compared in Table 2. The mean values of the total pulmonary pressure (TRP) and the mean pulmonary arterial pressure (mPAP) in NYHA class II are significantly different from those in class I. In addition, the mean value of right arterial pressure (mRAP) varied monotonically with the classification. These findings demonstrate the NYHA's advantage in $\mathrm{PH}$ prognosis. At the same time, though, the 6-minute walk distance, a classic test for heart failure patients, correlated poorly with the classification in $\mathrm{PH}$.

\section{PV loop measurements in different NYHA classes}

The PV loop measurements in three NYHA patient groups are summarized in Table 3 . As detected in the high NYHA classes (II and III), most of the mean values of the PV loop measurements were accelerated along with the deteriorated PH condition. Meanwhile, the RVEF and RVEes/Ea were inversely related to NYHA classes. Statistical analysis revealed significant differences of RVEDP and RVESP values between NYHA class I and those in higher NYHA classes (Figure 2).

\section{PV loop measurements correlated with NYHA classifications}

As shown in Table 4, the Pearson correlation test indicated that RVEDV, RVESV, RVEDP, and RVESP significantly correlated $(p<0.05)$ with the three NYHA classifications (I, II, and III). In addition, when the patients were grouped into two NYHA classifications (I and II/III), the classification had a significant association with RVESP and RVEa. When the patients were grouped into NYHA classes I/II and class III, this classification had a significant association with RVEDV, RVESV, and RVEDP. All these results suggest that PV loop measurements, especially RV variables, have significantly moderate correlations with NYHA classification (Figure 2). Right ventricular stroke volume, RVSV $(p=0.104)$ and left ventricular ejection fraction, $\operatorname{LVEF}(p=0.100)$ correlated essentially significantly with this grouping.

\section{ROC analysis of PV loop measurements in NYHA classification}

Next, we sought to evaluate the diagnostic and prognostic performance of the PV loop measurements in assessing the cardiac functional capacity of $\mathrm{PH}$ 
Table 1: Patient characteristics $(N=36)$

\begin{tabular}{|c|c|c|c|c|}
\hline Variable & Mean & SD & Minimum & Maximum \\
\hline \multicolumn{5}{|l|}{ Clinical data } \\
\hline Age (years) & 32.81 & 12.20 & 7.00 & 61.00 \\
\hline Height $(\mathrm{cm})$ & 157.69 & 9.95 & 125.00 & 174.00 \\
\hline Weight $(\mathrm{kg})$ & 50.83 & 9.95 & 28.00 & 74.00 \\
\hline $\operatorname{BSA}\left(\mathrm{cm}^{2}\right)$ & 1.51 & 0.18 & 0.97 & 1.84 \\
\hline BMI $\left(\mathrm{kg} / \mathrm{m}^{2}\right)$ & 20.34 & 2.99 & 15.05 & 27.85 \\
\hline $\operatorname{BMR}\left(\mathrm{kJ} / \mathrm{m}^{2} / \mathrm{h}\right)$ & 36.94 & 2.69 & 32.60 & 45.30 \\
\hline 6-MWD (m) & 446.42 & 11.29 & 305.00 & 520.00 \\
\hline HR (bpm) & 82.44 & 14.04 & 63.00 & 120.00 \\
\hline \multicolumn{5}{|l|}{ Medical history (\%) } \\
\hline Chest pain & $16.7 \%$ & & & \\
\hline Chest distress & $47.2 \%$ & & & \\
\hline Hemoptysis & $16.7 \%$ & & & \\
\hline Cyanosis & $44.4 \%$ & & & \\
\hline Dyspnea & $41.7 \%$ & & & \\
\hline Peripheral edema & $33.3 \%$ & & & \\
\hline \multicolumn{5}{|c|}{ Hemodynamic parameters } \\
\hline mRAP $(\mathrm{mmHg})$ & 7.86 & 4.79 & 4.00 & 25.00 \\
\hline mPAP $(\mathrm{mmHg})$ & 73.58 & 10.42 & 49.40 & 92.00 \\
\hline $\mathrm{TPR}\left(\mathrm{dyn} \cdot \mathrm{s} \cdot \mathrm{cm}^{-5}\right)$ & 981.06 & 625.57 & 78.39 & 2575.67 \\
\hline
\end{tabular}

Data given as the Mean or Percentage. BSA, body surface area; BMI, body mass index; BMR, basal metabolic rate; 6-MWD, six-minute walk distance; HR (bmp), heart rate (beats per minute); mRAP, mean of right atrial pressure; mPAP, mean of pulmonary arterial pressure; TPR, total pulmonary pressure.

patients [28]. ROC analysis was applied. Out of the 13 PV loop measurements we tested in correlation analysis, two measurements (RVEa and RVESP) were the most significant discriminators $(p<0.05, p<0.01)$ between both entities with areas under the curve of 0.871 and 0.903 respectively (Figure 3 ).

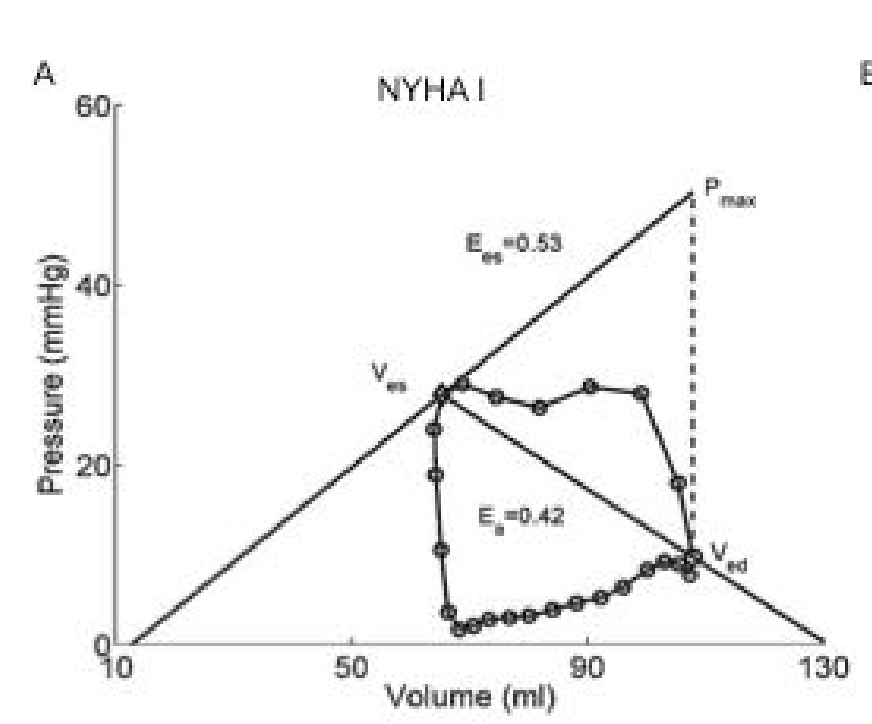

\section{DISCUSSION}

Although RV functional evaluation is mainly based on echocardiography technique in clinical practice, magnetic resonance imaging (MRI) appears to be the most accurate method for evaluating RV volume and

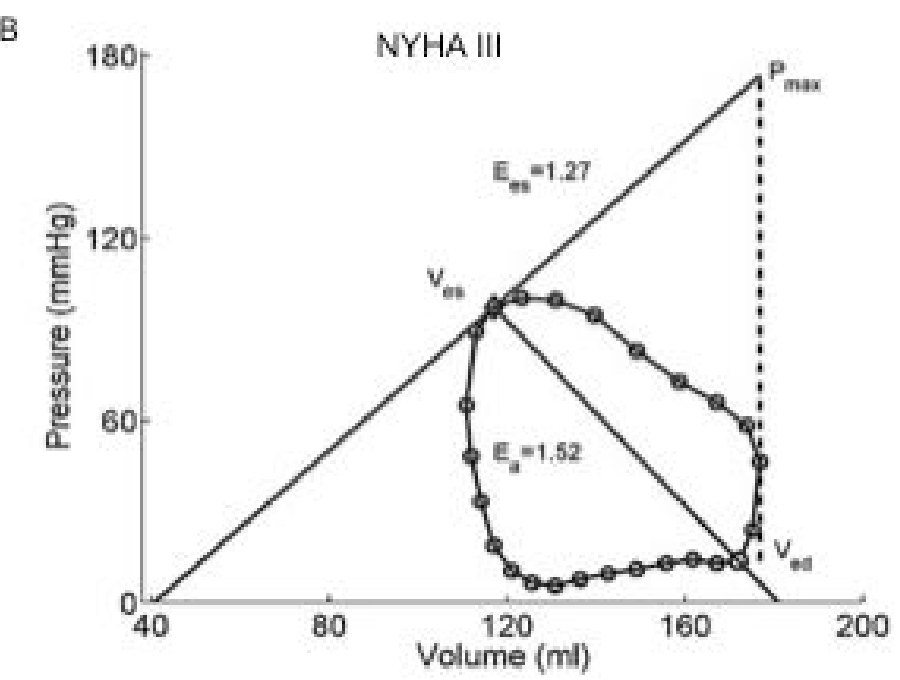

Figure 1: Representative PV loop graphs of NYHA class I patient (Panel A) and NYHA class III patient (Panel B). The PV loop measurements are: (A) RVEDV (mL), 107.9; RVESV (mL), 65.3; RVEF (\%), 40; Ees, 0.53; Ea, 0.42; Ees/Ea, 1.25; (B) RVEDV (mL), 172.1; RVESV (mL), 117.1; RVEF (\%), 40; Ees, 1.27; Ea, 1.52; Ees/Ea, 0.84. 


\begin{tabular}{lccc}
\hline & NYHA I & NYHA II & NYHA III \\
\hline Group\# & $1(n=5)$ & $2(n=23)$ & $3(n=8)$ \\
Age $($ year $)$ & $32.60 \pm 15.73$ & $30.39 \pm 10.10$ & $39.88 \pm 14.37$ \\
Male $(\%)$ & $40 \pm 55$ & $17 \pm 39$ & $50 \pm 53$ \\
Height $(\mathrm{cm})$ & $155.20 \pm 14.79$ & $156.17 \pm 8.02$ & $163.63 \pm 10.73$ \\
Weight $(\mathrm{kg})$ & $52.80 \pm 13.26$ & $49.57 \pm 8.82$ & $53.25 \pm 11.65$ \\
BSA $\left(\mathrm{cm}^{2}\right)$ & $1.51 \pm 0.24$ & $1.48 \pm 0.16$ & $1.57 \pm 0.18$ \\
BMI $\left(\mathrm{kg} / \mathrm{m}^{2}\right)$ & $21.66 \pm 2.85$ & $20.24 \pm 2.88$ & $19.79 \pm 3.50$ \\
BMR $\left(\mathrm{kJ} / \mathrm{m}^{2} / \mathrm{h}\right)$ & $37.90 \pm 4.31$ & $36.78 \pm 2.39$ & $36.78 \pm 2.65$ \\
HR $(\mathrm{bmp})$ & $84.80 \pm 10.73$ & $81.83 \pm 14.02$ & $82.75 \pm 17.21$ \\
Cardiothoracic ratio & $0.51 \pm 0.06$ & $0.57 \pm 0.09$ & $0.65 \pm 0.07 *$ \\
6-MWD $(\mathrm{m})$ & $434.00 \pm 88.17$ & $448.14 \pm 55.16$ & $452.50 \pm 86.57$ \\
mRAP $(\mathrm{mmHg})$ & $6.25 \pm 1.89$ & $6.522 \pm 2.61$ & $12.50 \pm 7.52$ \\
mPAP $(\mathrm{mmHg})$ & $30.40 \pm 17.24$ & $59.44 \pm 17.38^{* *}$ & $58.50 \pm 21.30^{*}$ \\
TPR $\left(\mathrm{dyn} \cdot \mathrm{s} \cdot \mathrm{cm}{ }^{-5}\right)$ & $447.50 \pm 242.70$ & $1069.217 \pm 549.57^{*}$ & $994.375 \pm 895.02$ \\
\hline
\end{tabular}

Data given as the Mean \pm SD. $* \& * * p<0.05^{\star} p<0.01$, compared to group \#1.

\section{A}
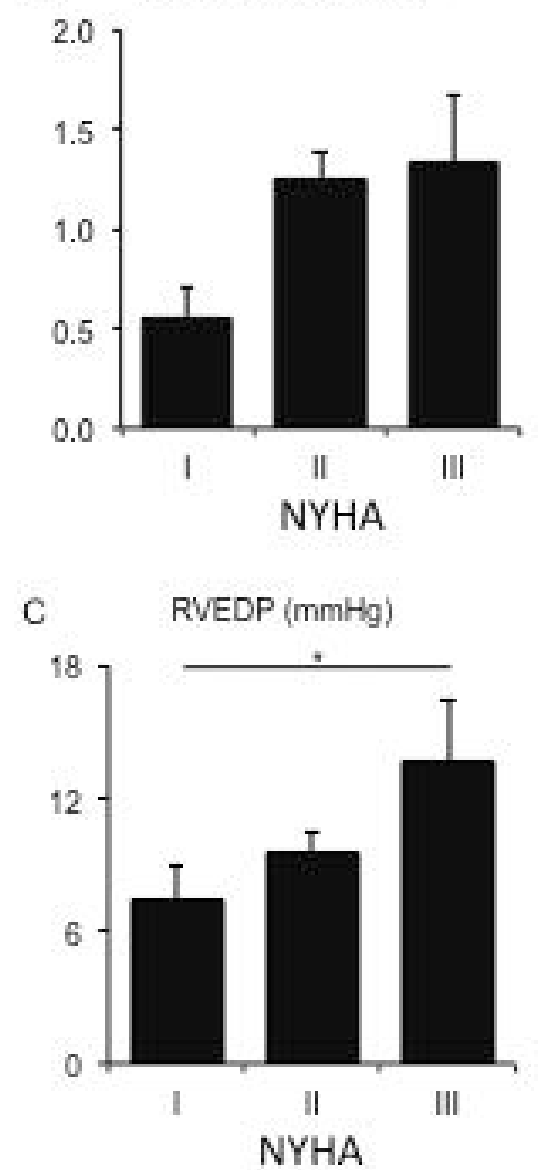
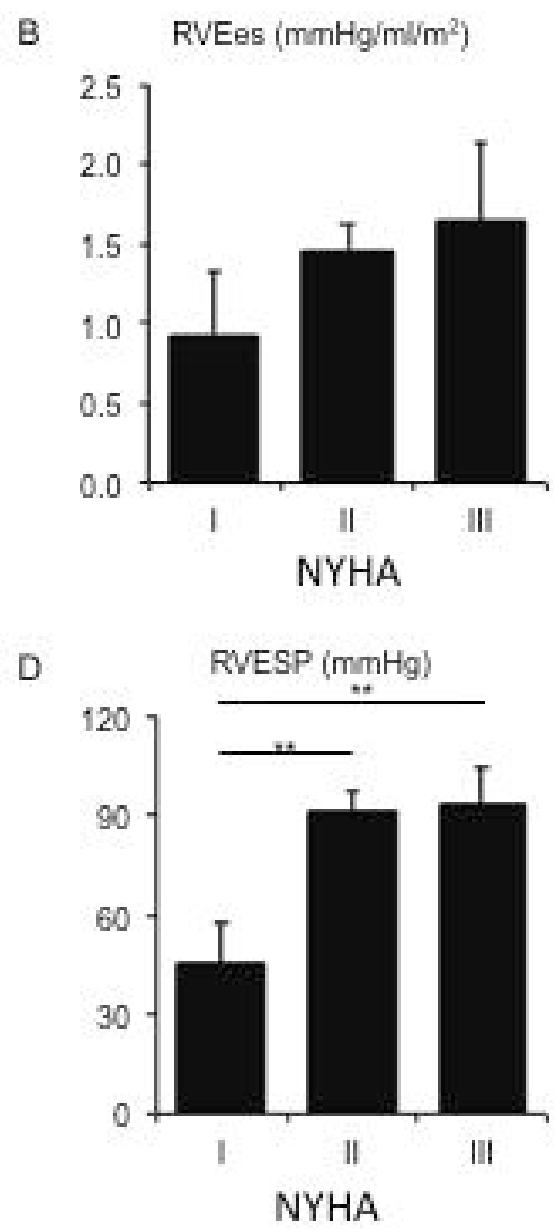

Figure 2: The mean values of RV arterial elastance (RVEa) (Panel A), RV end-systolic elastance (RVEes) (Panel B), RV end-diastolic pressure (RVEDP) (Panel C), and RV end-systolic pressure (RVESP) (Panel D) in different NYHA classes. 


\begin{tabular}{lccc}
\hline & NYHA I & NYHA II & NYHA III \\
\hline Group\# & $1(n=5)$ & $2(n=23)$ & $3(n=8)$ \\
$\operatorname{RVEDV~}\left(\mathrm{ml} / \mathrm{m}^{2}\right)$ & $144.04 \pm 96.66$ & $172.89 \pm 90.89$ & $285.10 \pm 199.03$ \\
$\operatorname{RVESV~}\left(\mathrm{ml} / \mathrm{m}^{2}\right)$ & $74.16 \pm 50.20$ & $97.35 \pm 73.78$ & $184.39 \pm 142.42$ \\
$\operatorname{RVSV}\left(\mathrm{ml} / \mathrm{m}^{2}\right)$ & $69.90 \pm 47.69$ & $75.54 \pm 33.63$ & $100.71 \pm 75.63$ \\
$\operatorname{RVEF}(\%)$ & $48.50 \pm 7.35$ & $48.02 \pm 15.53$ & $38.55 \pm 14.08$ \\
LVEDV $\left(\mathrm{ml} / \mathrm{m}^{2}\right)$ & $92.88 \pm 21.54$ & $102.80 \pm 46.70$ & $119.05 \pm 59.73$ \\
LVESV $\left(\mathrm{ml} / \mathrm{m}^{2}\right)$ & $41.24 \pm 20.34$ & $44.79 \pm 26.53$ & $61.31 \pm 35.82$ \\
LVSV $\left(\mathrm{ml} / \mathrm{m}^{2}\right)$ & $51.66 \pm 7.26$ & $58.00 \pm 25.58$ & $57.85 \pm 28.17$ \\
LVEF $(\%)$ & $57.06 \pm 10.37$ & $57.55 \pm 10.36$ & $50.53 \pm 10.50$ \\
$\operatorname{RVEDP}(\mathrm{mmHg})$ & $7.40 \pm 3.36$ & $9.61 \pm 4.31$ & $13.75 \pm 7.44 *$ \\
$\operatorname{RVESP}(\mathrm{mmHg})$ & $45.38 \pm 28.01$ & $91.37 \pm 29.62 * *$ & $93.45 \pm 30.56^{* *}$ \\
$\operatorname{RVEa}\left(\mathrm{mmHg} / \mathrm{ml} / \mathrm{m}^{2}\right)$ & $0.56 \pm 0.34$ & $1.25 \pm 0.63$ & $1.33 \pm 1.00$ \\
$\operatorname{RVEes~}\left(\mathrm{mmHg} / \mathrm{ml} / \mathrm{m}^{2}\right)$ & $0.93 \pm 0.87$ & $1.46 \pm 0.80$ & $1.65 \pm 1.36$ \\
$\operatorname{RVEes} / \mathrm{Ea}$ & $1.58 \pm 0.64$ & $1.20 \pm 0.48$ & $1.21 \pm 0.53$ \\
\hline
\end{tabular}

Data given as the Mean $\pm \mathrm{SD} .{ }^{*} \& * * p<0.05{ }^{\star} p<0.01$, compared to group $\# 1$. RVEDV, right ventricular end-diastolic volume; RVESV, right ventricular end-systolic volume; RVSV, right ventricular stroke volume; RVEF, right ventricular ejection fraction; LVEDV, left ventricular end-diastolic volume; LVESV, left ventricular end-systolic volume; LVSV, left ventricular stroke volume; LVEF, left ventricular ejection fraction; RVEDP, right ventricular end-diastolic pressure; RVESP, right ventricular end-systolic pressure; RVEa, right ventricular arterial elastance; RVEes, right ventricular end-systolic elastance.

RVEF [28]. Meanwhile, conductance catheterization represents the gold-standard method for evaluating RV pulmonary coupling measurements [29, 30]. In this study, these two powerful methods were adopted to obtain most hemodynamic and PV loop measurements to assess RV function in PH patients classified by the NYHA system. NYHA classification provides useful and complementary information about the presence and severity of heart failure (HF); it focuses more on exercise capacity and the symptomatic status of the disease [31]. However, this powerful and easily applied classification system has been criticized as an approximate and subjective tool, particularly in the RV functional discrimination between the asymptomatic class I and mildly symptomatic class
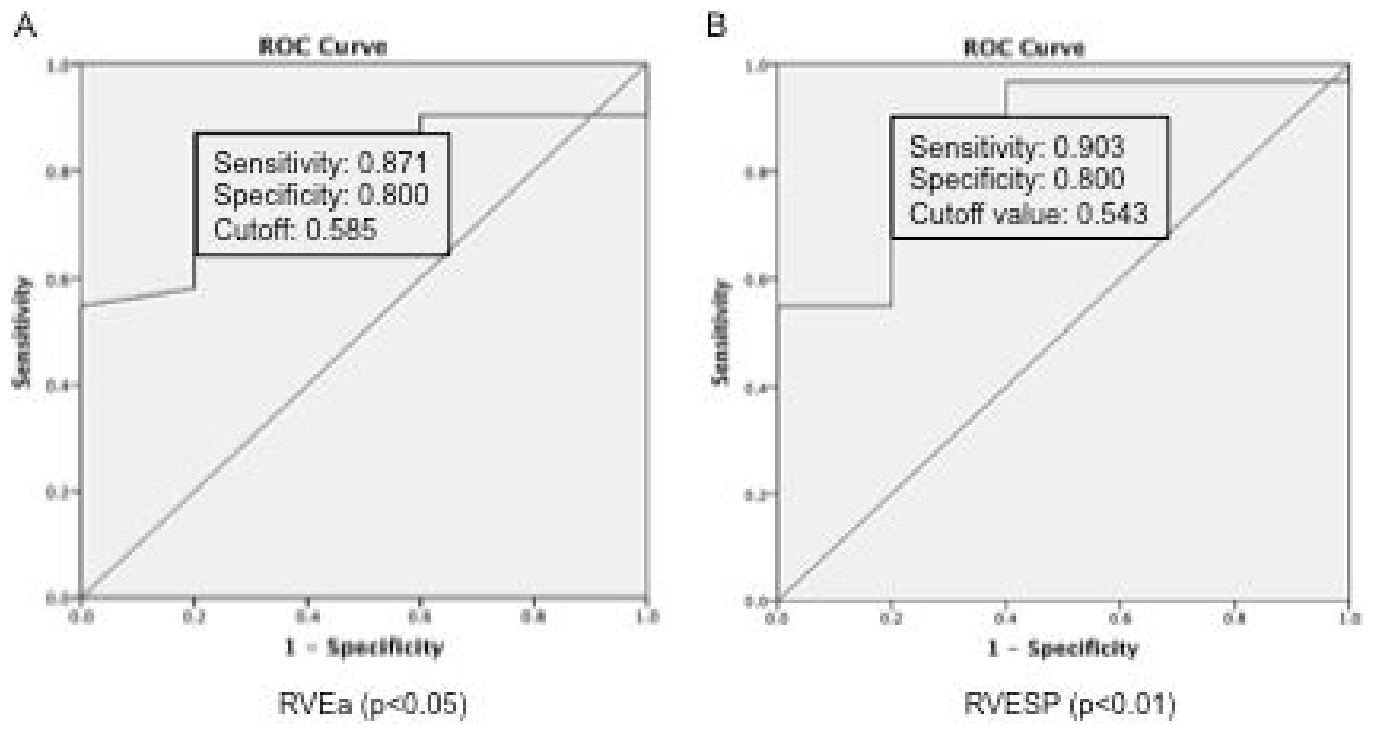

Figure 3: Receiver operating characteristic (ROC) curves of RVEa (Panel A) and RVESP (Panel B). ROC curves were constructed as plots of sensitivity versus 1 specificity when NYHA classes II and III were considered as positive. The values of sensitivity and specificity were indicated. 
II [6]. In our study, two PV loop measurements, RVESP and RVEa, correlated significantly (both $p$ values less than 0.05) with the grouping of class I, vs classes II and III (Table 4 and Figure 2). In chronic HF brought on by $\mathrm{PH}$, the right ventricle can adapt and remodel in response to the gradual increase in pulmonary vascular resistance (PVR) [32], like the left ventricle facing a progressive increase in systemic vascular resistance [33]. In the asymptomatic and mild phases of PH (in NYHA classes I and II), a homeometric adaptation of RV (i.e., without a chamber dilatation) occurs for the initial increase of RV afterload (RVEa) whose variation is bought by the change of PVR [30]. This adaptation mechanism primarily relies on the homeometric systolic function adaptation. Thus it interprets the good performances of RVEa, RVESP, and RV contractility independent of RV afterload, RVEes/ RVEa (RVEes normalized to RV afterload RVEa) on the discrimination of NYHA classification (class I and classes II/III). In this condition, RV and pulmonary are coupling well and RV variables either do not increase (RVEF) or increase slightly (RVSV, RVEDV, RVESV), compensated by the change in RV coupling whose surrogates are RVEes/RVEa and RVEDP [30] (Table 3). Based on this finding, we infer that the transition from class I to class II is probable at the middle or late stage of the RV homeometric adaptation process.

To distinguish patients between class II and III is crucial in a serious, reliable, reproducible assessment for a symptomatic patient because class III is the entry class for the end stage of the $\mathrm{PH}$ patient, and special therapeutic interventions are required for this end-stage patient population (i.e., in NYHA classes III and IV) [34-36]. Nevertheless, the NYHA classification's performance in making this distinction has been criticized for its unsatisfying interobserver agreement and its lack of consistency in classification; it is little better than chance [5]. Our finding demonstrates that RVEDV, RVESV, and RVEDP correlated significantly $(p<0.05)$ with the grouping of NYHA classes I/II and class III (Table 4 and Figure 2). RVEF was associated in an indicative significance $(p=0.104$, data not shown). When homeometric adaptation failure occurs, the systolic function adaptation is unable to afford the deterioration of $\mathrm{HF}$ in $\mathrm{PH}$, and $\mathrm{RV}$-pulmonary coupling uncouples, indicated by the maintained RVEes, RVEa, RVEes/RVEa, and RVESP in contrast with increased RV volumes between class II and class III (Table 3 ). It results in heterometric adaptation, mainly at the cost of the larger increases of RVEDV and RV wall thickness (represented by RVEDP) when RVEa remains too high (mean value of $\sim 1.30$ in this study) compared with its normal value range $[30,37]$. Table 3 shows that the mean values of RVEDV and RVEDP in NYHA class III were increased by $65.7 \%$ and $43.1 \%$ from class II, respectively, while the increments from class I to II are $19.4 \%$ and $29.9 \%$. The larger increase of RVESV, i.e., an $89.7 \%$ increment from class II to III compared with $31.1 \%$ from class I to II, is concomitant with this heterometric change in RV function. In addition, the failed RV pulmonary coupling in heterometric adaptation also leads to the decrease of RVEF. Though RVEDV has been substantially increased in this adaptation process in order to maintain the RVSV, the accelerating increase of RVSV (33\% increase from class II to III compared with $7 \%$ from class I to II) suggested that the function of this heterometric adaptation was deteriorating. In fact, the RVSV was closely associated with the limit of significance ( $p=0.171$, data not shown) with the grouping of classes I/II and class III (Table 4). Therefore, we infer that the transition from class II to III is probable at the upper intermediate or late stage of RV heterometric adaptation.

The normal right ventricle is a thin-walled and crescent-shaped flow generator and is generally unable to afford a brisk pressure increase from the pulmonary artery [38]. PH-induced RV HF is usually defined as a consequence of elevated RV afterload (RVEa) [28]; this corresponds to our finding that RVEa correlated with the NYHA classification of classes I, II, and III, residing on the edge of significance ( $p=0.095$, data not shown). In our results, RVEDV, RVESV, RVEDP, and RVESP correlated significantly $(p<0.05)$ with NYHA classes I, II, and III (Table 4). In reality, RV enlargement always occurs much earlier in the course of $\mathrm{PH}$, brought on by the increase of $\mathrm{RV}$ wall stress, compared with LV which can be interpreted mechanically by the fact that RV wall stress is greater for a comparable pressure increase as result of the smaller RV thickness [28, 39, 40]. This supports and explains our finding that the four aforementioned measurements positively correlated with NYHA classification (Table 4).

In the ROC analysis result (Figure 3), the RVEa and RVESP perform best among all PV loop measurements in predicting the level of $\mathrm{PH}$ according to NYHA classification $\left(\mathrm{p}_{\mathrm{RVEa}}<0.05 ; \mathrm{p}_{\mathrm{RVESP}}<0.01\right)$. These two measurements correlate significantly with the grouping of class I vs classes II/III (Table 3).

\section{Limitations}

There are several limitations to the present findings. First, this study was limited by the relatively small size of patients $(N=36)$ participating in the research. In addition, there was also a limited range of NYHA classes represented in the patient sample, i.e., with only five patients in class I and eight in class III, and null in class IV. However, the study was heavily dependent on outpatient environment and focused on less symptomatic PH patients; in such a context, this distribution of classes is common and acceptable.

\section{CONCLUSIONS}

The performance of these PV loop objective measurements indicates they are a possible alternative to the more qualitative NYHA classification system. 
RVESP and RVEa show a significant association with NYHA classifications (I and II/III). This finding is of capacity to distinguish the asymptomatic class I and mildly symptomatic class II, in which the traditional and prevailing NYHA always gains immense criticisms. And RVEDV, RVESV, and RVEDP have a significant association with NYHA classification (I/II and III). This finding is providing a more serious, reliable and reproducible assessment for symptomatic $\mathrm{PH}$ patients who is entering or may enter the end-stage. These results suggest PV loop measurements' promising role in assessing functional capacity in progressive but less symptomatic $\mathrm{PH}$ patients.

\section{ACKNOWLEDGMENTS AND FUNDING}

This work were supported by the National Natural Science Foundation of China (NSFC) through Grant 31330029; and the Wuhan Youth Program for Healthcare Scholars through Grant 201477; and Wuhan Chenguang Program of Science and Technology (Study of PressureVolume loop in Right Ventricle and Pulmonary Artery Integration, 2016); and National Medical Research Council (NMRC/OFIRG/0018/2016).

\section{CONFLICTS OF INTEREST}

None.

\section{REFERENCES}

1. Humbert M, Sitbon O, Chaouat A, Bertocchi M, Habib G, Gressin V, Yaïci A, Weitzenblum E, Cordier JF, Chabot F, Dromer C, Pison C, Reynaud-Gaubert M, et al. Survival in Patients With Idiopathic, Familial, and AnorexigenAssociated Pulmonary Arterial Hypertension in the Modern Management Era. Circulation. 2010; 122:156-163.

2. Pauwaa S, Machado RF, Desai AA. Survival in pulmonary arterial hypertension: A brief review of registry data. Pulmonary Circulation. 2011; 1:430-431.

3. Yuan JX, Rubin LJ. Pathogenesis of Pulmonary Arterial Hypertension: The Need for Multiple Hits. Circulation. 2005; 111:534-538.

4. Association. TCCotNYH. Nomenclature and Criteria for Diagnosis of Diseases of the Heart and Great Vessels. (Boston, Massachusetts: Little, Brown \& Co). 1994.

5. Raphael C, Briscoe C, Davies J, Whinnett ZI, Manisty C, Sutton R, Mayet J, Francis DP. Limitations of the New York Heart Association functional classification system and selfreported walking distances in chronic heart failure. Heart. 2007; 93:476-482.

6. Yap J, Lim FY, Gao F, Teo LL, Lam CSP, Yeo KK. Correlation of the New York Heart Association Classification and the 6-Minute Walk Distance: A Systematic Review. Clinical Cardiology. 2015; 38:621-628.

7. Cohn JN, Anand IS, Latini R, Masson S, Chiang YT, Glazer R, Investigators ftVHFT. Sustained Reduction of
Aldosterone in Response to the Angiotensin Receptor Blocker Valsartan in Patients With Chronic Heart Failure: Results From the Valsartan Heart Failure Trial. Circulation. 2003; 108:1306-1309.

8. McMurray JJ, Adamopoulos S, Anker SD, Auricchio A, Böhm M, Dickstein K, Falk V, Filippatos G, Fonseca C, Gomez-Sanchez MA, Jaarsma T, Køber L, Lip GY, et al. ESC Guidelines for the diagnosis and treatment of acute and chronic heart failure 2012. Eur J Heart Fail. 2012; 33:17871847.

9. Suga H. Ventricular energetics. Physiol Rev. 1990; 70.

10. Frank O. Die Grundform des arteriellen pulses: Mathematische Analyse. Erste Abhandlung. 1899.

11. Sagawa K. The ventricular pressure-volume diagram revisited. Circ Res. 1978; 43.

12. Suga H. Time course of left ventricular pressure-volume relationship under various enddiastolic volume. Jpn Heart J. 1969; 10.

13. Chirinos JA. Ventricular-arterial coupling: Invasive and non-invasive assessment. Artery research. 2013; 7.

14. Lee N, Taylor MD, Banerjee RK. Right ventricle-pulmonary circulation dysfunction: a review of energy-based approach. BioMedical Engineering OnLine. 2015; 14:1-20.

15. Faber MJ, Dalinghaus M, Lankhuizen IM, Steendijk P, Hop WC, Schoemaker RG, Duncker DJ, Lamers JM, Helbing WA. Right and left ventricular function after chronic pulmonary artery banding in rats assessed with biventricular pressure-volume loops. American Journal of Physiology Heart and Circulatory Physiology. 2006; 291:H1580-H1586.

16. Friedberg MK, Redington AN. Right Versus Left Ventricular Failure: Differences, Similarities, and Interactions. Circulation. 2014; 129:1033-1044.

17. Klotz S, Hay I, Dickstein ML, Yi GH, Wang J, Maurer MS, Kass DA, Burkhoff D. Single-beat estimation of enddiastolic pressure-volume relationship: a novel method with potential for noninvasive application. American Journal of Physiology - Heart and Circulatory Physiology. 2006; 291:H403-H412.

18. Zhang S, Yang Zg, Sun Jy, Wen Ly, Xu Hy, Zhang G, Guo Yk. Assessing Right Ventricular Function in Patients with Hypertrophic Cardiomyopathy with Cardiac MRI: Correlation with the New York Heart Function Assessment (NYHA) Classification. PLoS ONE. 2014; 9:e104312.

19. Chen $\mathrm{CH}$, Fetics B, Nevo E, Rochitte CE, Chiou KR, Ding PA, Kawaguchi M, Kass DA. Noninvasive single-beat determination of left ventricular end-systolic elastance in humans. Journal of the American College of Cardiology. 2001; 38:2028-2034.

20. Sunagawa K, Maughan WL, Sagawa K. Optimal arterial resistance for the maximal stroke work studied in isolated canine left ventricle. Circulation Research. 1985; 56:586-595.

21. Spruijt OA, de Man FS, Groepenhoff H, Oosterveer F, Westerhof N, Vonk-Noordegraaf A, Bogaard HJ. The 
Effects of Exercise on Right Ventricular Contractility and Right Ventricular-Arterial Coupling in Pulmonary Hypertension. Am J Resp Crit Care. 2015; 191:1050-1057.

22. Maron BJ, McKenna WJ, Danielson GK, Kappenberger LJ, Kuhn HJ, Seidman CE, Shah PM, Spencer Iii WH, Spirito P, Ten Cate FJ, Wigle ED, Vogel RA, Abrams J, et al. American College of Cardiology/European Society of Cardiology Clinical Expert Consensus Document on Hypertrophic Cardiomyopathy: a report of the American College of Cardiology Foundation Task Force on Clinical Expert Consensus Documents and the European Society of Cardiology Committee for Practice Guidelines. Journal of the American College of Cardiology. 2003; 42:1687-1713.

23. van de Veerdonk MC, Kind T, Marcus JT, Mauritz GJ, Heymans MW, Bogaard HJ, Boonstra A, Marques KMJ, Westerhof N, Vonk-Noordegraaf A. Progressive Right Ventricular Dysfunction in Patients With Pulmonary Arterial Hypertension Responding to Therapy. Journal of the American College of Cardiology. 2011; 58:2511-2519.

24. Gan CT, Holverda S, Marcus JT, Paulus WJ, Marques KM, Bronzwaer JG, Twisk JW, Boonstra A, Postmus PE, VonkNoordegraaf A. Right Ventricular Diastolic Dysfunction and the Acute Effects of Sildenafil in Pulmonary Hypertension Patients. Chest. 2007; 132:11-17.

25. Rain S, Handoko ML, Trip P, Gan CTJ, Westerhof N, Stienen GJ, Paulus WJ, Ottenheijm CAC, Marcus JT, Dorfmüller P, Guignabert C, Humbert M, MacDonald P, et al. Right Ventricular Diastolic Impairment in Patients With Pulmonary Arterial Hypertension. Circulation. 2013; 128:2016-2025.

26. Brimioulle S, Wauthy $\mathrm{P}$, Ewalenko P, Rondelet Bt, Vermeulen F, Kerbaul F, Naeije R. Single-beat estimation of right ventricular end-systolic pressure-volume relationship. American Journal of Physiology - Heart and Circulatory Physiology. 2003; 284:H1625-H1630.

27. Vanderpool RR, Pinsky MR, Naeije R, Deible C, Kosaraju V, Bunner C, Mathier MA, Lacomis J, Champion HC, Simon MA. RV-pulmonary arterial coupling predicts outcome in patients referred for pulmonary hypertension. Heart. 2015; 101:37-43.

28. Vonk-Noordegraaf A, Haddad F, Chin KM, Forfia PR, Kawut SM, Lumens J, Naeije R, Newman J, Oudiz RJ, Provencher S, Torbicki A, Voelkel NF, Hassoun PM. Right Heart Adaptation to Pulmonary Arterial Hypertension: Physiology and Pathobiology. Journal of the American College of Cardiology. 2013; 62:D22-D33.

29. Champion HC, Michelakis ED, Hassoun PM. Comprehensive Invasive and Noninvasive Approach to the Right Ventricle-Pulmonary Circulation Unit: State of the Art and Clinical and Research Implications. Circulation. 2009; 120:992-1007.
30. Kuehne T, Yilmaz S, Steendijk P, Moore P, Groenink M, Saaed M, Weber O, Higgins CB, Ewert P, Fleck E, Nagel E, Schulze-Neick I, Lange P. Magnetic Resonance Imaging Analysis of Right Ventricular Pressure-Volume Loops: In Vivo Validation and Clinical Application in Patients With Pulmonary Hypertension. Circulation. 2004; 110:2010-2016.

31. Yancy CW, Jessup M, Bozkurt B, Butler J, Casey DE, Drazner MH, Fonarow GC, Geraci SA, Horwich T, Januzzi JL, Johnson MR, Kasper EK, Levy WC, et al. 2013 ACCF/AHA Guideline for the Management of Heart Failure. Circulation. 2013; 128:e240-e327.

32. Naeije R, Manes A. The right ventricle in pulmonary arterial hypertension. European respiratory review. 2014; 23:476-487.

33. Sarnoff SJ, Mitchell JH, Gilmore JP, Remensnyder JP. Homeometric autoregulation in the heart. Circ Res. 1960; 8:1077-1091.

34. Mant J, Al-Mohammad A, Swain S, Laramée P; Guideline Development Group. Management of chronic heart failure in adults: synopsis of the National Institute For Health and clinical excellence guideline. Annals of Internal Medicine. 2011; 155:252-9.

35. Friedrich EB, Böhm M. Management of end stage heart failure. Heart. 2007; 93:626-631.

36. Cleland JG, Gemmell I, Khand A, Boddy A. Is the prognosis of heart failure improving? European Journal of Heart Failure. 1999; 1:229-241.

37. McCabe C, White PA, Hoole SP, Axell RG, Priest AN, Gopalan D, Taboada D, MacKenzie Ross R, Morrell NW, Shapiro LM, Pepke-Zaba J. Right ventricular dysfunction in chronic thromboembolic obstruction of the pulmonary artery: a pressure-volume study using the conductance catheter. Journal of applied physiology. 2014; 116:355-63.

38. Haddad F, Hunt SA, Rosenthal DN, Murphy DJ. Right ventricular function in cardiovascular disease, part I: Anatomy, physiology, aging, and functional assessment of the right ventricle. Circulation. 2008; 117:1436-48.

39. Suga H, Sagawa K, Shoukas AA. Load independence of the instantaneous pressure-volume ratio of the canine left ventricle and effects of epinephrine and heart rate on the ratio. Circ Res. 1973; 32.

40. Vonk-Noordegraaf A, Westerhof N. Describing right ventricular function. European Respiratory Journal. 2013; 41:1419-23. 